\title{
Movilidad y resistencia en producciones fílmicas de la comunidad nasa-páez (Cauca, Colombia)*
}

\author{
Lina Maritza Muñoz Márquez ${ }^{1}$ \\ University of Kansas (Estados Unidos)
}

\section{Resumen}

Para la comunidad nasa-páez del Cauca colombiano, los medios de comunicación como la radio, el internet y el video se han convertido en herramientas para fortalecer sus movimientos de resistencia mediante el Tejido de comunicación para la verdad y la vida. Teniendo en cuenta las concepciones que tienen en esta comunidad sobre los desplazamientos y la movilidad del pueblo nasa, así como los estudios de Deleuze y Guattari sobre espacios y movilidad, en este artículo, se analizan dos producciones fílmicas nasas Jiisa Wece /Raíz del conocimiento Nasa (Cineminga, 2012) y País de los pueblos sin dueños (Tejido de Comunicación y ACIN, 2009). Particularmente, se explora cómo las narrativas y estéticas de ambos se conectan a través del principio de pensamiento en espiral que hace parte de la cosmovisión nasa y, además, generan diversos procesos de movilidad física y simbólica que contribuyen a la constitución de un discurso contrahegemónico contra los proyectos estatales que han contribuido al desplazamiento

\section{Abstract}

For the Nasa-Páez community of the Colombian Cauca, distinct forms of media, like radio, internet and film, have become tools to strengthen their resistance movements through their "Tejido de la comunicación para la verdad y la vida" (web of communication for truth and life). Taking into account the conceptions surrounding displacement and mobility of the Nasa people as well as the Deleuze and Guattari studies about spaces and mobility, this article analyzes two Nasa films Jiisa Wece /Raíz del conocimiento Nasa (Cineminga, 2012) and País de los pueblos sin dueños (Tejido de Comunicación and ACIN, 2009). In particular, this article explores how the films' narratives and aesthetics are connected through the principle of a spiral movement mindset pertaining to the Nasa worldview, and how they generate various processes of physical and symbolic mobility that contribute to the creation of a counterhegemonic discourse against certain state projects that have contributed to the forced displacement of this

\footnotetext{
* Mobility and resistance in film productions of the nasa-páez community (Cauca, Colombia)

1 Magister Lina Muñoz Márquez. Candidata a doctora del Departamento de español y portugués de la Universidad de Kansas. Correo electrónico: linam@ku.edu.
} 
forzado de esta comunidad al ser desposeída de sus territorios.

Palabras clave: cine comunidad nasa páez, movilidad, desplazamiento forzado en Colombia, Manuel Quintín Lame, resistencia nasa-páez. community by depriving them of their territories.

Keywords: Nasa-Páez film, mobility, forced displacement in Colombia, Manuel Quintín Lame, Nasa-Páez resistance.

Ariruma Kowii (2005), un intelectual de la comunidad indígena kichwa de Otavalo-Ecuador, explica algunos principios que permiten entender cómo los diversos pueblos indígenas no han desaparecido pese a las violentas acciones de genocidio y etnocidio. Entre estos principios kichwas, describe el principio de la movilidad o el kuyuri, que garantiza la innovación permanente de las prácticas culturales. Desde esta perspectiva, la movilidad simboliza vida, renovación, continuidad (282). En la cosmovisión de varias comunidades del Abya Yala (término kuna utilizado por diversas comunidades indígenas para referirse al continente americano), este movimiento tiene la forma de espiral. El pensamiento en espiral permite tener una relación particular con el pasado conectándolo con el presente para la construcción colectiva del futuro. Este modelo de pensamiento y acción, a diferencia del pensamiento lineal, "permite generar y compartir conocimientos y experiencias colectivamente, y en cada contexto tanto los individuos como el colectivo se desarrollan simultáneamente. En un modelo en espiral, el conocimiento y los procesos históricos pueden comenzar en cualquier punto de la espiral y nunca tendrán un fin" (Gavilán, 2011: 18). Aunque este modelo hace parte del pensamiento de diversas comunidades indígenas ${ }^{2}$, cada una tiene sus propias concepciones.

Para la comunidad indígena tzetlal de Chiapas, México, por ejemplo, "el caminar en el caracol nos hace vivir y nos recuerda que nuestra movilidad tiene un sentido: buscar la vida [...] Caminar en el caracol es recordar que cada pueblo tiene sus caminos, pero todos queremos CAMINAR EN UN SÓLO CORAZÓN para cuidar la vida en el lugar donde vivimos y a donde vayamos" (Articulación Ecuménica, 2009: 13). Para la comunidad indígena nasa-páez ${ }^{3}$,

2 Gavilán (2011) explica que el pensamiento en espiral "lo mantuvieron escondido las Machi, los Negempin y los Weipife de la nación mapuche en los actuales territorios de Chile y Argentina. También lo mantuvieron los Aymaras y los Quechuas en las altas montañas de Bolivia, Perú y Ecuador, los Aztecas en México y los Maya-Quiche de Centro América, como asimismo los Lakotas, Comanches, Siksicas y Tssu Tina en Los Estados Unidos y Canadá" (7).

3 El pueblo indígena nasa es generalmente llamado también páez. Rappaport 
ubicada en el departamento del Cauca, en la zona andina al suroeste de Colombia,

[...] la espiral es el icono de la permanencia, el ciclo de vida del ser, es el cordón del ombligo, el ir y venir una y otra vez en el espacio y tiempo cotidiano de los nasa. Es un símbolo que se evoca realizándose en las prácticas del calendario agrícola. Señala el camino de la luna y el sol, ellos son los que determinan épocas de siembra y cosecha. Así mismo, permanece subyacente en los tejidos de las jigras de las mujeres nasa, cuando tejen enrollan y desenrollan, así es la vida, el sentir-pensar de los nasa, llena de tramas. Subyace en los rituales donde se danza y ofrenda a los espíritus de la naturaleza. En síntesis, la espiral es el estar del nasa en una relación indisoluble y armónica con su entorno (Piñacué, 2014: 182).

El pensamiento en espiral también se refleja en el movimiento de resistencia y los proyectos de desarrollo que los nasa han creado como respuesta a la violencia que han tenido que enfrentar, puesto que ha sido una de las comunidades más golpeadas por el conflicto armado colombiano y por el desplazamiento forzado. Parte de este movimiento de resistencia en busca de justicia, de la recuperación de sus territorios y de su autonomía ha sido el planteamiento de un plan estratégico o "Plan de vida" que se ha desarrollado desde comienzos del siglo XXI y, como lo explica Manuel Rozental, ha estado fundamentado en tres puntos: "consolidar autonomía, resistir y tejer con otros pueblos o 'hacer minga'” (cit. en Polanco Uribe y Aguilera Toro, 2011: 69). La estructura del "Plan de vida", dirigido por la Asociación de Cabildos Indígenas del Norte del Cauca -ACIN-, ha estado basada en diversos proyectos comunitarios o "tejidos": Tejido económico ambiental, Tejido de educación, Tejido de salud, Tejido de defensa de la vida, Tejido de la mujer, Tejido de justicia y armonía, y Tejido de comunicaciones para la verdad y la vida.

Este último tejido "forma parte de las estrategias con las que cuenta el movimiento indígena del Norte del Cauca para vincularse con el 'exterior' y posicionarse como agente político importante en el contexto nacional e internacional a través de un trabajo intensivo que combina los medios propios y los apropiados" (Rueda Ortíz, 2011: 35). Además, como lo afirma la comunicadora nasa Vilma Rocío Al-

(2005) explica que "nasa" es el término usado en la lengua nasa yuwe, y "páez" es una versión hispanizada de la época de la conquista (281). En adelante, utilizaré solamente el término nasa para referirme a esta comunidad. 
mendra, es concebido desde el pensamiento en espiral, ya que "la comunicación indígena surge y se orienta desde la Ley de Origen, se fortalece desde lo espiritual, trasciende a lo familiar comunitario y se evidencia en las prácticas de vida que orientan el camino de los pueblos" (cit. en Mora, 2012: 143). Dentro de este "Tejido de comunicación", se encuentran diversos medios de comunicación como la radio, por ejemplo, la emisora Radio Pa'yumat; las diversas páginas web, como la página de la ACIN, y el video como las producciones fílmicas que se estudiarán en este trabajo: Jiisa Wece /Raíz del conocimiento NASA (Cineminga, 2012) y País de los pueblos sin dueños (Tejido de Comunicación y ACIN, 2009).

En este artículo analizaremos particularmente cómo, en Jiisa Wece /Raíz del conocimiento NASA y País de los pueblos sin dueños, se teje una narrativa alrededor del principio de la movilidad en espiral, dado que, partiendo del personaje de Manuel Quintín Lame, tema central de Jiisa Wace, se muestra cómo se ha ido desenvolviendo la resistencia de los nasa, los caminos que ha ido tomando y la manera en que se ha ido fortaleciendo desde comienzos del siglo XX hasta épocas más recientes, tema central de País de los pueblos sin dueño. Como se ejemplifica en estas producciones fílmicas, la resistencia nasa ha estado marcada por desplazamientos cargados de significados simbólicos que le han permitido a esta comunidad recorrer, en términos de Deleuze y Guattari (2004), "espacios estriados" (citadinos, institucionalizados, regulados) para construir "espacios lisos" (abiertos a la transformación, dispuestos a la confrontación) (487) en los que se logre obtener justicia para las comunidades indígenas colombianas, oprimidas por los proyectos nacionales y transnacionales que se han dado desde el siglo XIX hasta la fecha.

Para Deleuze y Guattari (2004), en los espacios institucionalizados o "estriados", los trayectos están perfectamente planeados, calculados y referenciados. Por el contrario, en los espacios "lisos", los trayectos no dependen de las referencias determinadas y calculadas, sino que se dan de manera más aleatoria (487). Así mismo, los espacios también son definidos por la manera en cómo se recorren. Un espacio se puede recorrer de manera estriada (viajar en estriado), es decir, teniendo en cuenta referencias y trayectos establecidos, o de maneras lisas (viajar en liso), no institucionalizadas (490) que se convierten en puntos de fuga para los seres que han quedado al margen. Las políticas de la movilidad, generalmente, se constituyen desde los espacios institucionalizados, dado que, como lo afirman Adey y Bevan, "la movilidad ha de ser entendida dentro de los contextos sociales. Más que un lienzo en blanco sobre el que la movilidad tiene lugar, el espacio ha de ser percibido como 
un espacio estriado por las relaciones y las prácticas sociales" (cit. en Barriendos, 2007: 162). No obstante, grupos sociales marginados conciben formas diferentes de movilidad para recorrer, de una manera lisa, estos espacios estriados.

Estereotípicamente definidas en oposición a los valores occidentales de la modernidad y definidas como sociedades estáticas, fuera de lugar o nómadas en búsqueda de la mera supervivencia (Carey y Lydon, 2014: 6), las comunidades indígenas no solo han configurado espacios lisos al margen del control estatal, sino que han encontrado estrategias para recorrer, de manera lisa, los espacios estriados, organizados y gubernamentalizados. Estas formas de movilidad indígena les permiten encontrar caminos alternos a las únicas posibilidades que la modernidad occidental les ha dejado: la aculturación, el mestizaje o la desaparición.

Elementos y productos encontrados en estos espacios estriados, como los medios audiovisuales, son herramientas de las que se han apropiado diversos pueblos indígenas para hacer y darle significado a los recorridos "lisos" de esos espacios. A diferencia de García Canclini (2001), quien considera la inclusión de elementos occidentales en la cultura indígena como una forma de hibridación ${ }^{4}$, Schiwy (2009) ve estos fenómenos como procesos de "indigenización". Indigenizar el cine se refiere "a la capacidad de las culturas indígenas de integrar elementos europeos a su propio orden simbólico y social" (Shiwy, 2009: 13). El uso de la cámara y de las herramientas de edición les permite a los productores indígenas crear una estética audiovisual basada en la oralidad y en sus concepciones particulares del tiempo y el espacio, para construir, desde su mirada, las propias representaciones de su cultura y su cosmovisión.

\section{Jiisa Wece / Raíz del conocimiento NASA (Cineminga, 2012)}

En este documental, se contrastan los espacios estriados colombianos de principios de siglo XX y las maneras en que los indígenas empezaron a recorrerlos para recuperar su derecho a la tierra. Durante esa época, los espacios estriados estaban constituidos alrededor de una dinámica territorial y de poblamiento basada en "la expropiación y desterrito- rialización de los pueblos indígenas iniciada con

\footnotetext{
4 Néstor García Canclini (2001) en su libro Culturas híbridas: estrategias para entrar y salir de la modernidad, habla de la hibridación como "un proceso de intersección y transacciones que hace que la multiculturalidad evite lo que tiene de segregación y pueda convertirse en interculturalidad" (20). En su connotación de hibridez, en lugar de proponer una sociedad homogenizada, analiza las "múltiples" hibridaciones que se dan en los continuos contactos culturales.
} 
la expedición de la Ley 11 de 1821 que consideró a los indígenas libres e iguales a los demás colombianos y ordenó la repartición de los Resguardos, empujando a varios indígenas a las áreas montañosas y boscosas, y expulsándolos de las tierras productivas o convirtiéndolos en jornaleros, aparceros y otras variantes de la economía campesina" (Villa y Houghton, 2005: 27).

Manuel Quintín Lame (1880-1967) surge en esta época como un líder indígena que emprende un proceso de desterritorialización, en términos de Deleuze y Guattari, al aprender a recorrer estos espacios "estriados" de una manera "lisa" para recuperar la autonomía indígena sobre sus resguardos. Perteneciente a las comunidades indígenas del Gran Cauca, "una región esclavista, racista y señorial en la que la violencia socio-racial había sido particularmente aguda" (Espinosa, 2007: 406), se convierte en el jefe de un movimiento revolucionario indígena que se opone a estas discriminaciones raciales y al pago del terraje, y que busca la defensa de los resguardos y cabildos indígenas (Espinosa, 2007: 408). Para desplazarse por estos espacios estriados, Quintín Lame adquiere conocimientos básicos en derecho y busca asesoría jurídica para aprender a defender él mismo el derecho que poseían los indígenas a las tierras de sus ancestros. Sin embargo, para él, su mayor fuente de conocimiento la obtiene de su territorio y de la naturaleza que lo contiene.

En su manuscrito Los pensamientos del indio que se educó en las selvas colombianas (1924), que presenta diversos temas, describe la relación del indígena con la naturaleza, los procedimientos legales de la época, y hace una crítica a la élite del Cauca y sus departamentos aledaños. Este texto se convirtió en una "herramienta indispensable para la educación política de las comunidades indígenas" (Rappaport, 1989: 34) y, por tanto, en un elemento fundamental para el movimiento indígena que adquiere el nombre "Quintín Lame".

Aunque sobre este personaje existen numerosos estudios académi$\cos ^{5}$, el documental Jiisa Wece /Raíz del conocimiento presenta, desde el punto de vista de los indígenas nasa, el significado que tiene la imagen de Quintín Lame para su comunidad. Narrado en español y en lengua nasa, Jiisa Wece /Raíz del conocimiento es un proyecto colaborativo entre cineastas indígenas y productores externos a su comunidad. La cámara, el guión, la narración, las personas que aparecen en escena y la banda sonora estuvieron a cargo de los nasa.

5 Para Rapapport (1989) "la cantidad de publicaciones y tesis en torno a Quintín Lame y su obra (Castillo-Cárdenas 1987; Castrillón 1973; Fajardo Sánchez et. al. 1999; Rappaport 2000b; Romero Loaiza 2003a; Tello 1982; Theodosiadis 2000) indica la amplia difusión del texto entre los intelectuales blancomestizos y extranjeros" (35). 
Así mismo, su narración forma un tejido que comprende diferentes técnicas como la dramatización, el archivo fotográfico y las entrevistas; y la narrativa simboliza el pensamiento de espiral, ya que parte de la vida de Quintín Lame, y va mostrando el camino que la movilización indígena de esta comunidad ha ido tomando.

La estética del documental permite que tanto el contenido como el formato capturen diferentes momentos de la movilidad de los indígenas nasa. Al recrear la vida de Quintín Lame, el documental resalta los desplazamientos que tuvo que hacer para insertarse en el discurso legal hegemónico y desde allí luchar por sus derechos y los de su comunidad. Igualmente, muestra cómo los significados que adquirió esta movilidad y lo que representó se renuevan y adquieren nuevos significados en las generaciones actuales.

En Jiisa Wece /Raíz del conocimiento, se combina el formato documental con la ficción, lo que lleva a que lo identifiquen generalmente como un docudrama. Mediante la dramatización, se recrea la movilidad de Quintín Lame al principio de siglo XX y la presencia de su espíritu en el imaginario indígena actual; mediante el documental, se muestra el impacto de su legado y la movilidad del pueblo nasa en el día de hoy. Es así como en este filme se realizan varios recorridos siguiendo el pensamiento en espiral: al pasado, a los espacios físicos actuales de los resguardos indígenas y al mundo espiritual nasa.

Las primeras escenas del filme marcan estos tres desplazamientos. En la primera, aparece Quintín Lame en el espacio "estriado" de la ciudad de Bogotá, personificado por el indígena nasa Pio Quinto Oteca, quien es entrevistado en su despacho por una periodista. Mediante esta estrategia, se presentan los datos biográficos de Quintín. La escala de tonos sepia, los planos de las calles empedradas de la ciudad, el vestuario y el espacio cerrado de una oficina indican tanto la ubicación temporal, a comienzos del siglo XX, así como la localización en un espacio urbano. En contrapunto, hay un jump cut que presenta el siguiente plano con una toma tecnicolor en la que prevalece el color verde de las montañas, que se contrasta con los colores sepia de la secuencia anterior.

En esta toma, hay un desplazamiento temporal al presente y un desplazamiento físico por el espacio "liso" de los resguardos indígenas nasas que hay actualmente en Lame, Tierradentro, Cauca. Mediante varios paneos de la cámara, acompañados por la música extradiegética, se describe la belleza de este lugar. En los siguientes planos, la cámara empieza a recorrer los espacios comunitarios de los indígenas: la cocina comunitaria y el salón comunal donde se congregan varios indígenas en una reunión dirigida por una de las 
actuales líderes indígenas nasas, Aida Quilcuét. Quilcué se refiere al legado de Quintín Lame, al resaltar la importancia de recuperar la esencia nasa, dado que, aunque aprender de las ideologías externas es importante, considera que es más importante aprender sobre sus comunidades y trabajar por ellas.

En la tercera escena, hay un desplazamiento al mundo espiritual nasa. Mediante otro jump cut, se salta a otra secuencia en la que aparecen diferentes planos de elementos naturales, el agua, el sol y las montañas, mientras que se escucha la voz en off de un indígena hablando en lengua nasa. Esta voz describe que son estos elementos de la naturaleza los que les proporcionan el entendimiento y, cómo la vida en la montaña y el saber relacionarse con la gente fue lo que formó el conocimiento de Quintín Lame. A continuación, aparece el espíritu de Quintín Lame en medio de un ritual en el que le habla a los espíritus de la naturaleza.

Los desplazamientos temporales a la época de Quintín Lame, los recorridos por espacios citadinos y por los resguardos indígenas de aquella época y de la actualidad, y el mundo espiritual nasa se entrelazan para formar la narrativa en espiral del documental. Por ejemplo, cuando Quintín Lame sale de su resguardo y se dirige a las ciudades de Bogotá, Popayán e Ibagué para hacer visibles, ante los demás ciudadanos, las luchas que estaba librando. A este respecto, el Quintín Lame del documental afirma: "En Ibagué hablé [a la gente sobre que] no hay justicia para nosotros. El pueblo aplaudía, las autoridades mudas y sordas". En Bogotá, también solicitó entrevistarse con el presidente y éste no lo quiso atender.

Sus desplazamientos no solo se dan en estos espacios citadinos. En el documental, también se muestra que las formas de Quintín Lame para articular su lucha consistieron en la concienciación de los indígenas sobre los derechos que poseían. Con este fin, Quintín Lame va a los luga- res a los que habían sido desplazados los indígenas para mostrarles los derechos que tenían y fortalecer la reconfiguración de los Cabildos y la recuperación de las tierras de sus resguardos. Dada la inconformidad que generó en las élites el movimiento de Quintín Lame, éste fue enviado a prisión muchas veces en los diferentes lugares que recorría, de los cuales logró salir gracias a la defensa que él mismo hacía.

6 De acuerdo al Human Rights Annual Report 2008, Aida Quilcué es reconocida nacional e internacionalmente por denunciar la violación de los derechos humanos en las comunidades, incluyendo los asesinatos por parte del gobierno (House of Commons: Foreign Affairs Committee, 2009: 78). 
En el documental, además, hay una mezcla de los datos biográficos del líder indígena con los rituales de los indígenas nasa, para mostrar que el espíritu de Quintín Lame pervive en su comunidad. En el minuto14:92, hay un desplazamiento a la localidad de Ortega, donde se encuentra la sepultura de Quintín Lame. En este momento, se celebra el ritual Cxapuc en el que hacen ofrendas de alimentos a las ánimas. La voz en off explica que, para los nasa, los espíritus de los muertos siguen vivos, "son solo un viento pero nos dejan mucha inspiración. Por eso, reorientamos nuestra vida. Los ancestros siguen vivos, nos dan su fuerza. Por eso, decimos que nuestros abuelos no han muerto. Están vivos”.

En esta parte del documental, el espíritu de Quintín Lame aparece comunicándose con la naturaleza, así como también hace presencia en medio de la comunidad actual con la pretensión de enterarse de los problemas que hoy los aquejan y la misión aún viva de transmitirle a su pueblo la importancia de trabajar juntos por sus resguardos y cabildos, dándose cuenta de que los problemas que existían en su época siguen vigentes: "Ya con cabildos pensé que tendrían armonía, pero el blanco con su politiquería trajo la plata de transferencias y, por ese dinero, estamos en peleas. Jamás parece haber remedio. Por eso, yo regreso para enfrentar estos problemas. Ahora tenemos que volver a hablar y orientarnos otra vez". Este espíritu, que es representado en Jiisa Wece /Raíz del conocimiento mediante la ficción, aparece en el siguiente documental que analizaremos, País de pueblos sin dueños, como parte de un movimiento indígena contemporáneo que llevó al desplazamiento de los nasa desde sus resguardos hasta los espacios estriados de la ciudad, al igual que el movimiento de Quintín Lame. Jiisa Wece /Raíz del conocimiento nos permite observar una estética audiovisual indígena que contribuye a crear un discurso contrahegemónico al visibilizar la movilidad indígena mediante el uso de técnicas fílmicas como el jump cut, la movilidad de planos, y la movilidad fluida entre ficción y documental.

\section{País de los pueblos sin dueños}

Los problemas actuales que afectan a la comunidad indígena nasa $\mathrm{y}$, en general, a todos los indígenas colombianos, siguen siendo similares a los que se tuvieron que enfrentar Quintín Lame y los pueblos indígenas en su época: el problema por el derecho a la tierra. De hecho, podría decirse que se ha agudizado, dada la violencia ejercida en los sectores rurales por parte del ejército, la guerrilla y los paramilitares. La violencia política, en particular, es una de las formas en que el Estado recorre de manera estriada los espacios lisos que habitan los indígenas y de los que han pretendido apoderarse 
militarizando las zonas y destinando los territorios para el desarrollo de proyectos multinacionales. Sin embargo, estas condiciones de violencia han propiciado que, en las comunidades indígenas del Cauca (principalmente la nasa), ilegitimen las acciones de esos tres sectores y se generen "fuertes procesos de afirmación en términos de autogobierno, jurisdicción indígena y control territorial" (Villa, 2005: 113-114).

Para Deleuze y Guattari (2004), donde "hay líneas de articulación o de segmentaridad, estratos, territorialidades; [...] también hay líneas de fuga, movimientos de desterritorialización y de desestratificación" (9-10), así como también operaciones de "reterritorialización" que permi- ten recuperar la estabilidad (93). Estas operaciones se dan mediante un "agenciamiento colectivo", definido por estos autores como "las transformaciones in-corporales que tienen lugar en una sociedad determinada, y que se atribuyen a los cuerpos de esa sociedad" (85). Las luchas indígenas por recuperar su autonomía, tanto en la época de Quintín Lame como en la actualidad, logran conformarse gracias al agenciamiento colectivo de la comunidad y a una movilidad indígena cargada de significados.

Estos significados adquieren forma en el documental País de los pueblos sin dueño, el cual hace parte de una trilogía ${ }^{7}$ de documentales realizada por el Tejido de Comunicaciones de la ACIN entre 2005 y 2009. En este documental, se registra la marcha hacia Bogotá de la Minga ${ }^{8}$ Social y Comunitaria de los nasa, para rechazar políticas neoliberales como el Tratado de Libre Comercio con Estados Unidos y la militarización de sus territorios. Este documental no solo denuncia los atropellos de un gobierno que beneficia a los intereses de un sistema neoliberal, sino que resalta los significados que se desprenden de ese desplazamiento desde su territorio hasta la capital, para que, más allá de la denuncia, construya una reflexión política para todo el país. El movimiento alcanza a percibirse como una espiral, puesto que tiene como protagonista a la colecti- vidad nasa que reúne a diferentes sectores sociales marginados del país y recibe apoyo de ellos, formando un cordón que está fundamentado en la trayectoria de resistencia nasa (como se vio en el documental Jiisa Wece /Raíz del conocimiento Nasa), pero que va sumando diferentes actores sociales que se sienten identificados con esta movi-

7 Los otros dos documentales son $P a^{\prime}$ poder que nos den tierra y Somos alzados en bastones de mando. El primero trata sobre la recuperación de la hacienda El Japio, en Caloto, y el segundo, sobre los reclamos por el incumplimiento de viejos acuerdos durante la Cumbre Nacional Itinerante (Mora, 2012: 47).

8 “Minga”, en quechua "Minka”, es una tradición de diversas comunidades indígenas latinoamericanas en la que se trabaja colectivamente con el fin de lograr un bien común. 
lización. En este contexto, este documental es una herramienta utilizada para evidenciar tres puntos fundamentales de la movilidad: registrar recorridos físicos y discursivos que el pueblo nasa hace a los espacios estriados estatales, representar los significados que se desprenden de estos desplazamientos y dinamizar nuevas formas de movilidad.

El documental se convierte en un elemento fundamental en esta movilización indígena no solo porque narra los diferentes momentos que constituyen este desplazamiento (su origen, el desarrollo y el desenlace), sino porque se convierte en un discurso contra lo hegemónico. Al poner en contrapunto los planos que se toman en directo a medida que se desarrollan los sucesos, con el discurso que el gobierno emite mediante los medios de comunicación nacional, se contrasta la voz indígena que rechaza la intervención violenta del ejército en sus territorios y la intransigencia del gobierno que se niega a atender sus peticiones, con la voz del gobierno que desmiente la intervención violenta del Estado en estos territorios y justifica sus proyectos neoliberales. Al inicio del documental, uno de los indígenas expresa el motivo por el cual se ha conformado este movimiento. Según él, esta minga social y comunitaria se da porque

[...] nos sentimos amenazados por un plan de muerte, que viene implementando guerra y terror [...] nos mata la guerrilla, nos matan los paramilitares, nos mata la fuerza pública y también nos agreden con las leyes de manera muy sistemática, las leyes están simplemente respondiendo al interés corporativo, al interés internacional y no al interés del pueblo [...]. Igualmente, aparecen en este momento los tratados de libre comercio que son un instrumento que utilizan las corporaciones para apoderarse de los territorios, para apoderarse de la soberanía nacional y poner el sistema estatal al servicio de sus intereses [...] esos son los motivos que nos llevan a levantarnos y decir no más a esto y proponemos una construcción de una agenda común de resistencia de los pueblos que nos permita defendernos frente a esta agresión.

Como ejemplo de esta violencia estatal frente al movimiento pacífico de los indígenas, se realizan varias tomas en las que se contrastan los policías disparando a los indígenas, quienes solo tienen como armas piedras y bastones. La respuesta del gobierno desde es acusarlos de estar aliados con los guerrilleros, negar la intervención violenta de la policía y, por el contrario, posicionar a los policías como víctimas. 
Los discursos que el presidente Álvaro Uribe Vélez ${ }^{9}$ y el comandante de la policía dan en los noticieros pierden validez al ser contrastados con las escenas de violencia que han registrado los indígenas. Dos muertos y varios heridos, policías disparando y bloqueando la carretera y un agente del ejército infiltrado entre los indígenas son hechos que, en lugar de atemorizarlos, les dan fuerza para seguir con su objetivo, como lo manifiesta uno de los indígenas que lidera la minga:

Este gobierno no nos ha cumplido, nos sigue matan-
do, nos sigue asesinando. No obstante, de eso somos
capaces de reponernos, recoger nuestros muertos y
nuestros dolores y salir a convocar al resto de la socie-
dad para que seamos nosotros los que construyamos
ese país para todos y todas, [...] seguiremos caminando
la palabra de esta gran minga con rumbo a la ciudad
de Cali, vamos a caminar con todos y todas para ver si
algún día tenemos una Colombia de los pueblos y sin
dueños, y no como es ahora, una Colombia con dueños
y sin pueblos.

Estas palabras se presentan en una voz en off mientras la cámara empieza a registrar el desplazamiento que, a pie, hace un gran número de indígenas cuando se dirigen al espacio citadino con el objetivo de establecer un diálogo con el presidente. La respuesta que encuentran es simbolizada mediante una silla vacía que demuestra la falta de voluntad para dialogar por parte del gobierno.

Sin embargo, como lo afirma una de las lideresas indígenas, tuvieron que morir muchas personas para que Uribe aceptara realizar un debate que fue solicitado cuatro años atrás. Aceptando la invitación de los indígenas, Uribe se desplaza hasta uno de los resguardos indígenas para escu- charlos. No obstante, la posición inflexible del mandatario que respalda las políticas neoliberales, que, según él, benefician a todo el país, hace que el diálogo se convierta en un monólogo y no se tengan en cuenta los puntos de vista de los indígenas. El gobierno ignora la cultura y la ideología de un pueblo que exige la autodeterminación para la administración de sus recursos naturales. Esta imposibilidad de diálogo y debate entre indígenas y gobierno impulsa la convocatoria de una minga nacional que se dirige a la capital.

Los diferentes desplazamientos que se registran en el documental están cargados de significados que revelan las pretensiones del

9 Álvaro Uribe Vélez fue presidente de Colombia durante los períodos 2002-2006 y 2006-2010. Actualmente es senador de la república colombiana por el partido Centro Democrático fundado y dirigido por él. 
documental: de manera pacífica, buscan alcanzar la autonomía indígena sobre sus territorios. Para lograrlo, la cámara registra y simboliza el agenciamiento colectivo de la comunidad nasa. Por un lado, registra la organización de los cabildos indígenas, sus formas de ejercer justicia de una manera didáctica más que violenta ${ }^{10}, \mathrm{y}$ su capacidad para confrontar al Estado y de convocar no solo a los pueblos indígenas, sino a la nación. Por otro lado, la apropiación que hacen de la cámara, como una de las principales armas que tienen en este movimiento, simboliza su autonomía para construir discursos propios que confronten los discursos hegemónicos.

A diferencia del movimiento y el documental de Quintín Lame, donde se le dio completo protagonismo a este líder, en País de los pueblos $\sin$ dueño, el protagonismo lo tiene la comunidad, el cuerpo colectivo, los cabildos, que tiempo atrás Quintín Lame ayudó a reconstituir. Muestra de ello radica en que la mayoría de las secuencias están compuestas por planos exteriores y panorámicos que se centran en las mingas comunitarias o reuniones de pueblos indígenas hermanos, amigos y víctimas del Estado colombiano. Aparecen diferentes líderes, pero no se incluye el nombre de ninguno, ya que representan la voz de todos los que luchan por alcanzar un bienestar común.

La toma de las carreteras también está cargada de significados. Esas vías pavimentadas que se destinan al transporte de los recursos que les extraen a las comunidades indígenas y campesinas y que garantizan la presencia represora del Estado, sirvieron, en ese momento, como máquinas hiladoras donde cada fibra, cada indígena, se unirían para tejer un puente de comunicación entre las minorías, los demás ciudadanos y el Estado. Los ataúdes de cartón que cargan durante sus marchas no solo simbolizan las víctimas del conflicto, sino la forma en que su filosofía de vida está siendo acribillada por el Estado. En uno de los planos que muestran la marcha hacia Cali, uno de los indígenas afirma: "los indios amamos la vida, los indios tenemos un plan de vida, el gobierno tiene un plan de muerte, un plan de extinción y ese plan de muerte es la Seguridad Democrática ${ }^{11}$, es

10 Vemos un ejemplo de esto en el minuto 8:08 cuando los representantes de los diferentes cabildos deciden dar una amonestación pública al infiltrado del ejército, dándole 8 "juetazos (latigazos) espirituales" en frente de toda la comunidad.

11 El gobierno de Álvaro Uribe Vélez "se estructuró de manera principal bajo la política denominada de Seguridad democrática, que comportaba un tratamiento exclusivamente militar de los grupos guerrilleros y una negociación controversial con las organizaciones paramilitares, muy lejana de los estándares internacionales de verdad, justicia y reparación. Pero, al mismo tiempo, continuó y profundizó las orientaciones de corte neoliberal y de reorganización del Estado, acordes con la fase actual del capitalismo" (Angarita Cañas, 2011: 26). Además, como se ha señalado en este y otros estudios (Derechos humanos y transformación política en contextos de violencia (2015) y El embrujo autoritario (2003)), durante la presidencia de Uribe 
el TLC, es el estatuto de desarrollo rural. Ese plan de muerte es la ley $1150^{12 " . ~ A d e m a ́ s, ~ l o s ~ a t a u ́ d e s ~ s e ~ c o n v i e r t e n ~ e n ~ u n ~ s i ́ m b o l o ~ p a r a ~}$ visibilizar, en los espacios estriados y ante los citadinos, la violencia política de la que son víctimas los indígenas.

Finalmente, puede observarse cómo el documental captura y dinamiza nuevas formas de movilidad dentro de la comunidad y de la comunidad hacia afuera. La minga, que al inicio del documental está conformada únicamente por indígenas, se convierte en una minga nacional que pretende incidir en la conciencia de todos los colombianos y representar la voz de todos los ciudadanos que han sido marginados y desatendidos por el gobierno. La cámara es utilizada para crear conciencia en la ciudadanía. De la misma manera que Quintín Lame pretendía concienciar a los indígenas de la época con respecto a los derechos que tenían y que no les eran reconocidos, los líderes nasa de hoy día, asumen la misma tarea, pero no solo al interior de su comunidad, sino entre los sectores marginados de la sociedad. En el minuto 32:42 del documental, uno de los líderes indígenas manifiesta que éste es uno de los objetivos de la minga, ya que, debido a las arduas jornadas laborales y a la manipulación de la televisión, esos sectores de la sociedad colombiana desconocen sus derechos y, por ende, les son vulnerados.

El propósito de la minga trasciende dado que los indígenas logran encontrarse con el país. La cámara captura varios actos simbólicos como el intercambio de herramientas entre indígenas y campesinos, y el sentimiento de confraternidad de diferentes sectores expresado mediante ofrendas culturales como la música y elementos de supervivencia como ropa y alimentos y, voces de ánimo y bienvenida por los lugares que cruzaban. Al llegar a Bogotá, y al tomarse el Parque Nacional, la minga ha logrado congregar no solo a las comunidades indígenas, sino a diversos grupos como los afrocolombianos, el sector de la salud y las víctimas de los crímenes de Estado. Esta minga mostró la posibilidad de una transformación en la sociedad colombiana. Las emociones y el afecto que transmite el documental dejan abiertas las puertas a una continua reflexión sobre el cambio que necesita la sociedad y el gobierno colombiano.

se violaron los derechos humanos de la población civil mediante eventos como los desplazamientos forzados y los falsos positivos (jóvenes de los sectores pobres del país que asesinados por las fuerzas militares para hacerlos pasar por guerrilleros muertos en combate), siendo las comunidades populares, la sociedad civil organizada, los opositores, entre otros "los sectores sociales [...] más vulnerados en sus libertades fundamentales” (Coordinación Nacional Plataforma, 2003:14).

12 La ley 1150 de 2007 establece la forma de contratación con recursos públicos a personas jurídicas o naturales, del sector privado o público. 


\section{Conclusión}

El análisis de estos documentales ha permitido ampliar la comprensión del significado que el video ha adquirido en las comunidades indígenas colombianas, particularmente la nasa, para, siguiendo el pensamiento en espiral, realizar diversos desplazamientos en el tiempo y en el espacio. Para recuperar la memoria histórica sobre el líder indígena nasa Manuel Quintín, los videastas indígenas utilizan diferentes técnicas fílmicas y sus concepciones espirituales para manifestar que la presencia del espíritu revolucionario del indígena aún habita en su comunidad. La alternancia entre ficción, realidad y su cosmovisión espiritual crean una dinámica en el documental que transgrede los discursos hegemónicos que han afectado a esta comunidad. Esto mismo se observa en País de los pueblos sin dueño, en el que la cámara se convierte en una de las principales armas y herramientas para formar la minga nacional en contra de las políticas neoliberales. Ambos movimientos, en el tiempo y en el espacio, están cargados de significados y puntos de fuga que les permiten a estas comunidades transitar por los espacios estriados de la ciudad para luchar por sus derechos.

Esta movilidad indígena ha contribuido a la creación de espacios lisos en los que convergieron diferentes grupos marginados por políticas estales diseñadas al servicio de los terratenientes de comienzos del siglo XX y de las multinacionales del siglo XXI. El video documental se ha convertido en uno de los puntos de fuga mediante el cual los indígenas han registrado y simbolizado sus luchas y logros en la recuperación de su autonomía, tanto para autorepresentarse en el imaginario de su comunidad y de la sociedad en general, como para ejercer una agencia colectiva que les permita abrir la posibilidad de una transformación social, en la que se tengan en cuenta sus puntos de vista sobre la manera en cómo se administra la justicia y cómo se protegen los recursos naturales del país. La movilidad adquiere nuevos matices y significados en los contextos de los pueblos indígenas que, en lugar de ser comunidades estáticas, están en continuo cambio, revitalizando sus valores tradicionales con los elementos tecnológicos que ofrece la modernidad occidental, como lo es el cine que, en la comunidad nasa particularmente, contribuye al fortalecimiento de la minga y del Tejido de comunicación.

\section{Bibliografía}

Angarita Cañas, P.E. (2011). Seguridad democrática. Lo invisible de un régimen político y económico. Bogotá: Siglo del Hombre Editores. 
Articulación Ecuménica Latinoamericana de Pastoral Indígena (2009). Movilidad/Migración desafío y esperanza para los pueblos. VI Encuentro Latinoamericano de Teología Indígena. Memoria del encuentro. Recuperado de http://www.padrenello.com/wp-content/uploads/2014/02/E-Book-VI-Encontro-Continental-de-Teologia-\%C3\%8Dndia-Espanhol.pdf

Barriendos Rodriguez, J. (2007). El arte global y las políticas de la movilidad. Desplazamientos (trans)culturales en el sistema internacional del arte contemporáneo. Revista LiminaR. Estudios sociales y humanísticos, 5 (V, 1), 159-182. Recuperado de http://www.redalyc.org/pdf/745/74550110.pdf

Carey, J. \& Lydon J. (2014). Introducción. En Carey, J. y Lydon J. (Eds) Indigenous Networks: Mobility, Connections and Exchange. Nueva York y Londres: Routledge.

Cineminga (Producción y dirección) (2012). Jiisa Wece /Raíz del conocimiento NASA. Colombia.

Coordinación Nacional Plataforma Colombiana de Derechos Humanos, Democracia y Desarrollo (2003). Introducción. En Paredes, N. (Ed.) El embrujo autoritario. Primer año de gobierno de Álvaro Uribe Vélez. Bogotá: Plataforma Colombiana de Derechos Humanos, Democracia y Desarrollo.

Deleuze, G. \& Guattari, F. (2004). Mil Mesetas. Capitalismo y esquizofrenia. Valencia: Pre-textos.

Espinosa, M. Manuel Quintín Lame. (2007). Pensamiento colombiano del siglo XX, Volumen 2. Santiago Castro-Gómez et al (eds.) Bogotá: U Pontificia Javeriana, 403-434.

García Canclini, N. (2001). Culturas híbridas: estrategias para entrar y salir de la modernidad. Buenos Aires: Paidos.

Gavilán, V. (2011). El pensamiento en espiral- El paradigma de los pueblos indígenas. Santiago de Chile: Ñuke Mapuförlaget.

House of Commons: Foreign Affairs Committee. (2009). Human Rights Annual Report 2008. Londres: The Stationery Office.

Kowii, A. (2005). Barbarie, civilizaciones e interculturalidad. En C. Walsh (Ed.) Pensamiento crítico y matriz (de)colonial reflexiones latinoamericanas. Quito: Abya-Yala.

Mora, P. (2012). Poéticas de la resistencia. El video indígena en Colombia. Bogotá: Cinemática Distrital.

Piñacué Achicue, J.C. (2014). Pensamiento indígena, tensiones y academia. Tabula Rasa, 20, 161-192. 
Polanco Uribe, G. \& Aguilera Toro, C. (2011). Luchas de representación. Prácticas, procesos y sentidos audiovisuales colectivos en el suroccidente colombiano. Cali: Programa Editorial, Universidad del Valle.

Rappaport, J. Manuel Quintín Lame hoy. (1989). Revista del Centro Cultural Universitario Aquelarre, 33-58. . (2005). Intercultural Utopias: Public Intellectuals, Cultural Experimentation, and Ethnic Pluralism in Colombia. Durham y Londres: Duke University Press.

Rueda Ortíz, R.(2011). Introducción. En Quiguanás, V. A., Giraldo, C. D., Gómez Zúñiga, R., González Mina, J., Grillo, O., Henao Velarde, A., ...Unás Camelo, V. (Eds.) Tierra Tierra y silicio: Cómo la palabra y la acción política de pueblos indígenas cultivan entornos digitales. Santiago de Cali: Programa Editorial Universidad del Valle.

Schiwy, F (2009). Indianizing film. Decolonization, the Andres and the Question of Technology. New Jersey: Rutgers.

Tejidos de Comunicación de Asociación de Cabildos Norte del Cauca -ACIN- (Productor) y Acosta, M. (Director). (2009). País de los pueblos sin dueño. Colombia.

Villa, W. \& Houghton, J. (2005). Violencia política contra los pueblos indígenas en Colombia, 1974-2004. Bogotá: Alto vuelo. 